\title{
Tuberous sclerosis epilepsy and psychosis by adults
}

\section{Introduction}

The tuberous sclerosis (TS) or tuberous sclerosis complex (TSC) is a multisystem, autosomal dominant disorder by children and adults, results from mutations in one of two genes, TSC1 (encoding hamartin) or TSC2 (encoding tuberin). First described in depth by Bourneville in 1880 (Morbus Bourneville, Epiloa). ${ }^{1}$

TS and TSC often causes disabling neuropsychiatric disorders, including epilepsy, mental retardation, autism and psychosis. Additional major features of the disease include dermatologic manifestations such as facial angiofibromas, renal angiomyolipomas, and pulmonary lymphangiomyomatosis. TSC has a wide clinical spectrum of disease, and many patients have minimal signs and symptoms with or without neurologic and psychiatric disability. ${ }^{2}$

TS is one of "phakomatosis" a group of congenital hereditary developmental anomalies having selective involvement of tissues of ectodermal origin, which develop disseminated glial hamartomas. Examples of phakomatosis are neurofibromatosis, tuberous sclerosis, Sturge-Weber syndrome, and von Hippel-Lindau disease."”3

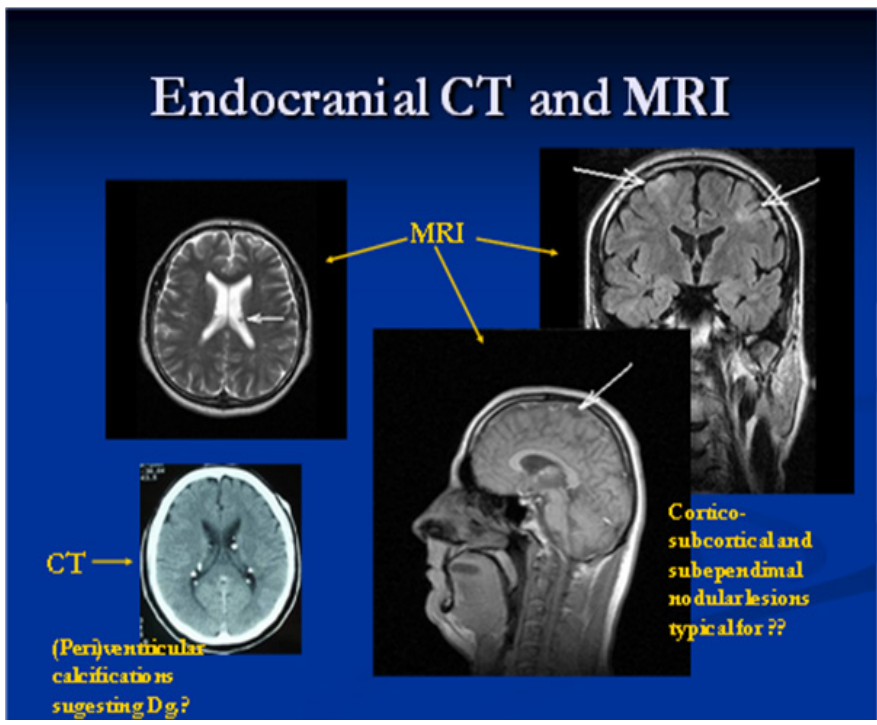

Figure I Typical skin lesion for Tuberous sclerosis.

The clinical dignostic criterias are divided in two groups: 1. Major criterias (facial angiofibroma, ungual fibroma, shagreen patch, hypomelanotic macula, cortical tuber, subependymal nodules, subependymal giant-cell tumor, retinal hamartroma, cardiac rhabdomioma, renal angiomyolipoma, lymphangiomatosis), and 2. Minor criterias (multiple pints in dental enamel, hamartomatous rectal polyps, bone cysts, cerebral white-matter radial migration lines, gingival fibromas, retinal achromic patch, "confetti" skin lesions groups of small lightly pigmented spots, multiple renal cysts). The diagnosis is fullfiled with two major features, or one major feature plus two minor features. ${ }^{4}$ Age of onset of some typical lesions is in fetal life (cortical tuber, cardiac rhabdomyoma), in infancy (ungual fibroma, hypomelanotic macula, retinal hamartroma, facial angiofibroma), in adolescence (shagreen patch, subependimal nodules, lymphangiomyomatosis) and in adulthood (renal angiomyolipoma).
Volume 8 Issue 6 - 2018

\author{
Andrej N llanković,' NikolaN Ilanković ${ }^{2}$ \\ 'Universitz Psychiatric Clinic, Dep. of Neuropszchiatrz, Serbia \\ ${ }^{2}$ General hospital "MEDIGROUP”, Serbia
}

Correspondence: Andrej N. llanković, MD, PhD, Ass Prof, Universitz Psychiatric Clinic, Dep. of Neuropszchiatrz, Belgrade, Serbia, Pasterova 2,Email ilankov@beotel.rs

Received: October 09, 2018 | Published: December 26, 2018

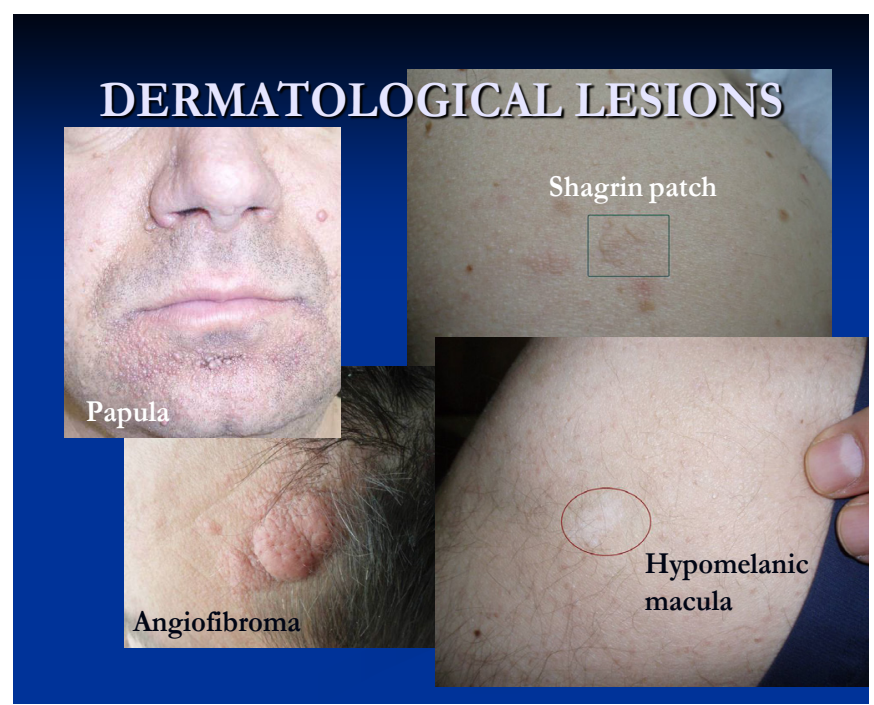

Figure 2 Typical endocranial (cortical, subcortical and subependymal) lesions by Tuberous sclerosis.

The molecular genetics analysis in multigenerational families and positional cloning were used to map both the TSC1 and TSC2 genes 3234 . The TSC2 gene, which is located on chromosome 16p13, encodes a transcript of $5.5 \mathrm{~kb}$ containing 41 exons and encompassing $40 \mathrm{~kb}$ of genomic DNA; there are several alternatively spliced versions. ${ }^{5}$ The TSC1 gene, which is located on chromosome 9q34, encodes a transcript of $8.6 \mathrm{~kb}$, containing 23 exons and encompassing $55 \mathrm{~kb}$ of genomic DNA.${ }^{6,7}$ It is the possibility to prevention of disease with chordocentesis and genetic analzsis in first 3 months of pregnancy.

By 5 patients ( 3 M, 2 F, average age 35, 7 years, from different part of forner Yugoslavia, mostly South Serbia)A, was admittet between 2013 and 2016) to University Clinic of Psychiatry in Belgrade (Serbia). Most (4 from 5) developed paranoid psychotic episodes 1 to 2 years prior to admission, epileptic seizures partialy and generalized ( 3 from 5), anxiety, disorders and depression. Most (4 from 5) was treated as with flufenazine $5 \mathrm{mg}$ per diem and chlorpromazine $25 \mathrm{mg}(3 \mathrm{x} 1)$, once patient was treated with haloperidol ( $5 \mathrm{mg}$ pro die), and all 5 patients with seizures with carbamazepine $(3 \times 200 \mathrm{mg})$ and phenobarbital (50$100 \mathrm{mg}$ in the evening). Referred to our clinic in 2007. and admitted 
first time to a complete neuropsychiatric exploration, because of increased frequency of seizures, hypertensive crisis, depression, worrying about work, paranoid psychotic elaboration.

In family history - bz all patients evidence of skin lesions. In physical examination in somatic findings the patients were afebrile, eupnoic, hypertensive $155 / 100 \mathrm{~mm} \mathrm{Hg}$ to $180 / 110 \mathrm{~mm} \mathrm{Hg}$, cardiopulmonally compensated. All have multiple red papules on facial skin, 3 patients larger angiofibroma in left frontal or parietal regions, multiple hypomelanic maculas on body and Shagrin patches on body skin. Psychiatric examination revealed discretely slowed flow of thinking, mild mental retardation and unsistematized persecutory delusions.

In neurological status - 4 patients have dayly 1-2 epileptic seizures (partial and partial with secondary generalization). During clinical examination additional diagnostic procedures were done. The typical EEG was hypersynchronous, alpha-theta type, $\mathrm{s}$ with single irritative bitemporal changes, more on the right or left side.

Endocranial CT showed periventricular calcifications suggesting probably TS. Endocranial MRI - cortico-subcortical and subependimal nodular lesions typical for Tuberous Sclerosis (TS).

Liver (Ultra Sound): multiple hiperehogenous changes, one susp.haemangioma Kidney (Ultra Sound): Left or right kidneys hypoechogenous nodules, many smaller, 5-6 cysts and calcificates., bzy all patients. Neuropsychological examinations (interview, VITI, TMT A, B; RAVLT, RCF, FF, KF, Rch): MMSE average 23/30, IQ average 70, showed: mild retardet, introverted and anxious personality, with tendencies to paranoid elaboration. The cognitive and affective changes bz all patients was organic origin.

\section{Discussion}

\section{Chronology of illness}

Epileptic seizures, typical skin lesions ((facial angiofibroma, shagreen patch), psychotic disorder (paranoid psychosis) and arterial hypertension (kidney origin) fullfiled all diagnostic criteria for Tuberous sclerosis: typical lesions of CNS (cortico-subcortical and subependimal nodular lesions), skin lesion, liver and kidneys nodules and cystes.
The patients was successfully treated wit symptomatic therapy: neuroleptica (antypsychotica), antiepileptica and antyhypertensive drugs/diuretica (flufenazine, 2,5 mg, carbamazepine, $400 \mathrm{mg}$, phenobarbitone, $100 \mathrm{mg}$, diazepam, $10 \mathrm{mg}$, hydrochlorothiazide, 1 tab. on second day. The result was reduced paranoid delusions and reduced frequency of seizures, reduced arterial hypertension.

\section{Conclusion}

According to the clinical presentation (epilepsy, mental retardation, multiple typical dermatological signs) and discovered patognomonic multysistemic changes (cortical and subcortical tubers, subependimal nodules, kidney and liver nodules and cysts), we must think about phacomatosisi and in most cases conclude that the diagnosis is Tuberous sclerosis.

Paranoid psychotic disorder by patient with symptomatic epilepsy (organic substrate + vulnerable personality) made this case even more complex, but due to psychiatric symptoms and epilepsy (as a starting point), we were able to initiate our search for etiology of the disorder and to go retrogradly to the cause. Tuberous sclerosis is very important in differential dignosis of many multisistemic disorders.

\section{References}

1. Bourneville DM. Sclerose tubereusedes circonvolutions cerebrales: idiotie et epilepsie hemiplegique. Arch Neurol (Paris). 1880;1:81-91.

2. Crino PB, Nathanson KL, Henske EP. The Tuberous Sclerosis Complex. N Engl J Med. 2006;355(13):1345-1356.

3. Dorland's Medical Dictionary for Health Consumers. (C) 2007 by Saunders, and Elsevier

4. Roach ES, Gomez MR, Northrup H. Tuberous sclerosis complex consensus conference: revised clinical diagnostic criteria. J Child Neurol. 1998;13(12):624-628.

5. Dabora SL, Jozwiak S, Franz DN, et al. Mutational analysis in a cohort of 224 tuberous sclerosis patients indicates increased severity of TSC2, compared with TSC1, disease in multiple organs. Am J Hum Genet. 2001;68(1):64-80. 